\title{
Kinetics of demineralization of shrimp exoskeleton in chitin and chitosan synthesis
}

\author{
Ameh A. O. ${ }^{1}$, Isa M. T. ${ }^{1 *}$, Adeleye T. J. ${ }^{1}$ and Adama K. K. ${ }^{2}$ \\ ${ }^{1}$ Department of Chemical Engineering, Ahmadu Bello University, Zaria, Nigeria. \\ ${ }^{2}$ Sheda Science and Technology Complex (SHESTCO), Sheda, Abuja, Nigeria.
}

Accepted 11 March, 2013

\begin{abstract}
Kinetic data obtained from acid demineralization (using $1.25 \mathrm{~N}$ hydrochloric acid solution) of deproteinized exoskeleton of shrimp was fitted to the shrinking core models for heterogeneous reactions. The element of interest was calcium which was the most abundant element in the deproteinized shrimp (66.27\%) and the mostly affected by the demineralization. Experimental kinetic data was fitted to the shrinking core model for fluid-particle reactions. Chemical reaction controlled mechanism gave the best predictive model, as depicted by the fit $\left(R^{2}=0.92\right)$, with a time of complete reaction of $3 \mathrm{~h}$.
\end{abstract}

Key words: Calcium, chitin, hydrochloric acid, shrinking core model.

\section{INTRODUCTION}

Chitin is a homopolymer of N-acetyl-D-glucosamine (Glc$\mathrm{NAc}$ ) residues linked by $\beta-1-4$ bonds. The main source of chitin is crustacean waste, which is also the main cell wall material in most fungi (Nicol, 1991). Chitin and its derivatives have high economic value owing to their versatile biological activities and agrochemical applications (Hirano, 1996; Wang and Huang, 2001), finding application in medical (Murugan and Ramakrishna, 2004; Yadav and Bhise, 2004) and pharmaceutical areas (Takeuchi et al., 2001; Kato et al., 2003). In spite of the presence of nitrogen, chitin may be regarded ascellulose with hydroxyl at position C-2 replaced by anacetamide group. Like cellulose, it functions as a structural polysaccharide. It is estimated that nearly 1011 tons of chitin is produced annually in the biosphere, much of it in the oceans (Poulicek and Jeuniaux, 1991). Chitin occurs in a range of organisms but is particularly important as constituent of arthropods (Muzzarelli, 1977). In extracting chitin from the shells of arthropods, demineralization and deproteinization are the basic purification processes involved (Rødde et al., 2008; Das and Ganesh 2010). Chitosan is a linear polymer of $\alpha$ $(1 \rightarrow 4$ )-linked 2-amino-2-deoxy- $\beta$-D-glucopyranose. It is synthesized by chitin deacetylation using concentrated sodium hydroxide solution. Its chemical makeup gives it a positive charge, which accounts for its ability to attract particles with a negative, or opposite, charge (Limam et al., 2011). As an industrial agent, it is applied during the water-filtration process to remove oils, heavy minerals and phosphorus from water (Mehdinejad et al., 2009). Sand filtration apparently can remove up to $50 \%$ of the turbidity alone, while the chitosan with sand filtration removes up to $99 \%$ turbidity.

Numerous works have considered the demineralization of the exoskeleton of arthropods using $\mathrm{HCl}$ (Rødde et al., 2008; Uno et al., 2012) with not much reported on the kinetics of the demineralization process. Understanding of the kinetics of the reaction can give more information for process control and development. The objective of this work was to study the kinetics of chitin synthesis with 
Table 1. Effect of time on the deproteinization of shrimp shells using $\mathrm{NaOH}$.

\begin{tabular}{cc}
\hline Deproteinization time (min) & Nitrogen content (\%) \\
\hline 0 & 6.74 \\
5 & 1.31 \\
10 & 1.4 \\
15 & 1.31 \\
20 & 1.4 \\
30 & 1.58 \\
\hline
\end{tabular}

a view to optimizing the chitin/chitosan synthesis process.

\section{Experimentation}

$40 \mathrm{~g}$ of shrimp shell was soaked and stirred in $3 \%$ solution of $\mathrm{NaOH}$ at variable times of 5 to $30 \mathrm{~min}$ by boiling at $95^{\circ} \mathrm{C}$ to deproteinize. The yield of deproteinized material was determined with time. At the optimum deproteinization time, the deproteinized shell was then soaked in $1.25 \mathrm{~N}$ solution of $\mathrm{HCl}$ acid at room temperature for times ranging from 20 to 100 min with stirring. Elemental composition was followed with time using XRF analysis. For the XRF analysis, standardless setting was used. At optimum demineralization time, the chitin obtained was deacetylated at 90 to $95^{\circ} \mathrm{C}$ using solution of $\mathrm{NaOH}(1: 1, w / w)$ (Limamet al., 2011). The chitosan obtained was characterized using SEM and XRD.

\section{RESULTS}

\section{Deproteinization}

Table 1 presents the result of the deproteinization using $\mathrm{NaOH}$ solution. Table 2 presents the elemental composition of the shells before deproteinization and after deproteinization with $\mathrm{NaOH}$ for 15 min.

\section{Demineralization}

Table 3 presents the elemental analysis of the demineralized shrimps (after deproteinization).

\section{Kinetics modeling}

Figure 1 presents the fit of the demineralization date to the chemical reaction controlled mechanism (CKC), diffusion through ash layer controlled mechanism (ALDF) and fluid film diffusion controlled mechanism (FFDC).

\section{Analysis of chitosan}

Figures 2 and 3 present the diffraction pattern and the SEM micrograph of the synthesized chitosan.
Table 2. Effect of deproteinization on the elemental composition of shrimp shells.

\begin{tabular}{lcc}
\hline \multirow{2}{*}{ Element } & \multicolumn{2}{c}{ Composition \% } \\
\cline { 2 - 3 } & A & B \\
\hline $\mathrm{Al}$ & 3.333 & 0.106 \\
$\mathrm{Si}$ & 1.915 & 0.411 \\
$\mathrm{~K}$ & 3.594 & $\mathrm{ND}$ \\
$\mathrm{Ca}$ & 46.962 & 66.269 \\
$\mathrm{Cr}$ & $\mathrm{ND}$ & $\mathrm{ND}$ \\
$\mathrm{Ti}$ & 0.058 & $\mathrm{ND}$ \\
$\mathrm{Mn}$ & 0.029 & 0.016 \\
$\mathrm{Fe}$ & 0.456 & 0.091 \\
$\mathrm{Ni}$ & $\mathrm{ND}$ & $\mathrm{ND}$ \\
$\mathrm{Cu}$ & 0.088 & $\mathrm{ND}$ \\
$\mathrm{Zn}$ & 0.016 & $\mathrm{ND}$ \\
$\mathrm{Ba}$ & 0.681 & $\mathrm{ND}$ \\
$\mathrm{Re}$ & 0.223 & $\mathrm{ND}$ \\
$\mathrm{Cd}$ & $\mathrm{ND}$ & 0.962 \\
\hline $\mathrm{Al}$
\end{tabular}

$\mathrm{A}=$ raw shell, $\mathrm{B}=$ deproteinized shell, $\mathrm{nd}=$ not detected.

\section{DISCUSSION}

As shown in Table 1, deproteinization was not significantly affected by time within the range considered: nitrogen content after deproteinization was $1.400 \pm 0.072$. Table 2 presents the elemental analysis (XRF) of the shrimp exoskeleton before and after deproteinization. The compositions of the metals in shrimp as shown in Table 2 are widely different from (larger than) reported elemental analysis using atomic absorption spectrometry (Adeleye et al., 2008; Rødde et al., 2008). The difference is most likely as a result of the standardless setting used in XRF analysis. However, the compositions presented by the XRF analysis indicate relative and not absolute concentrations as STANDARDLESS setting (Kataoka, 1989) was used in the analysis; the machine being unfamiliar with biological materials (matrix). Though the value of composition may not be absolutely correct, the trend (relative magnitude with respect to the matrix used by the standardless setting of the XFR) is correct. It is this trend that this works attempts to model. Table 2 show that the most abundant metal in both materials is $\mathrm{Ca}$ similar to (Adeleye et al., 2008; Rødde et al., 2008). However, the composition of potassium and zinc shown in Table 2 are relatively (that is when compared to the respective $\mathrm{Ca}$ content) much lower than that reported by Adeleye et al. (2008). In addition, $\mathrm{Mn}$ and $\mathrm{Na}$ reported by Adeleye et al. (2008) and Rødde et al. (2008) where undetected as shown in Table 2. Deproteinization enhanced the composition of $\mathrm{Ca}$ in the shell (increasing from 46.962 to 66.269). This was because $\mathrm{Ca}$ is insoluble in $\mathrm{NaOH}$, thus its concentrations in the remaining solid material increase after treatment with $\mathrm{NaOH}$. Similar 
Table 3. Concentration of elemental after deproteinization and the demineralized-deproteinized samples.

\begin{tabular}{lcccccc}
\hline \multirow{2}{*}{ Element } & \multicolumn{7}{c}{ \% Composition } \\
\cline { 2 - 7 } & $\mathbf{B}$ & $\mathbf{C}$ & $\mathbf{D}$ & $\mathbf{E}$ & $\mathbf{F}$ & $\mathbf{G}$ \\
\hline $\mathrm{Al}$ & 0.106 & $\mathrm{ND}$ & $\mathrm{ND}$ & $\mathrm{ND}$ & $\mathrm{ND}$ & $\mathrm{ND}$ \\
$\mathrm{Si}$ & 0.411 & 2.66 & 1.214 & 4.204 & 1.588 & 3.036 \\
$\mathrm{~K}$ & $\mathrm{ND}$ & $\mathrm{ND}$ & $\mathrm{ND}$ & $\mathrm{ND}$ & $\mathrm{ND}$ & $\mathrm{ND}$ \\
$\mathrm{Ca}$ & 66.269 & 43.174 & 37.005 & 12.581 & 17.513 & 5.447 \\
$\mathrm{Cr}$ & $\mathrm{ND}$ & 0.657 & 0.164 & 0.205 & 0.253 & 0.068 \\
$\mathrm{Ti}$ & $\mathrm{ND}$ & $\mathrm{ND}$ & 0.150 & 0.258 & $\mathrm{ND}$ & 0.120 \\
$\mathrm{Mn}$ & 0.016 & 0.310 & 0.124 & $\mathrm{ND}$ & $\mathrm{ND}$ & $\mathrm{ND}$ \\
$\mathrm{Fe}$ & 0.091 & 5.101 & 2.551 & 4.284 & 4.556 & 3.138 \\
$\mathrm{Ni}$ & $\mathrm{ND}$ & 0.700 & 0.134 & 0.385 & 0.472 & 0.503 \\
$\mathrm{Cu}$ & $\mathrm{ND}$ & 0.639 & 0.224 & 0.431 & 0.535 & 0.599 \\
$\mathrm{Zn}$ & $\mathrm{ND}$ & 0.241 & $\mathrm{ND}$ & 0.032 & 0.394 & 0.321 \\
$\mathrm{Ba}$ & $\mathrm{ND}$ & $\mathrm{ND}$ & $\mathrm{ND}$ & $\mathrm{ND}$ & $\mathrm{ND}$ & 0.090 \\
$\mathrm{Re}$ & $\mathrm{ND}$ & 3.383 & 1.230 & 2.076 & $\mathrm{ND}$ & 0.6921 \\
$\mathrm{Cd}$ & 0.962 & 5.249 & 6.999 & 16.623 & 21.873 & 22.747 \\
\hline
\end{tabular}

$\mathrm{B}=$ deproteinized shell, $\mathrm{C}=$ sample demineralized for $20 \mathrm{~min}, \mathrm{D}=$ sample demineralized for $40 \mathrm{~min}, \mathrm{E}=$ sample demineralized for $60 \mathrm{~min}, \mathrm{~F}=$ sample demineralized for $80 \mathrm{~min}, \mathrm{G}=$ sample demineralised for $100 \mathrm{~min}, \mathrm{nd}=$ not detected.

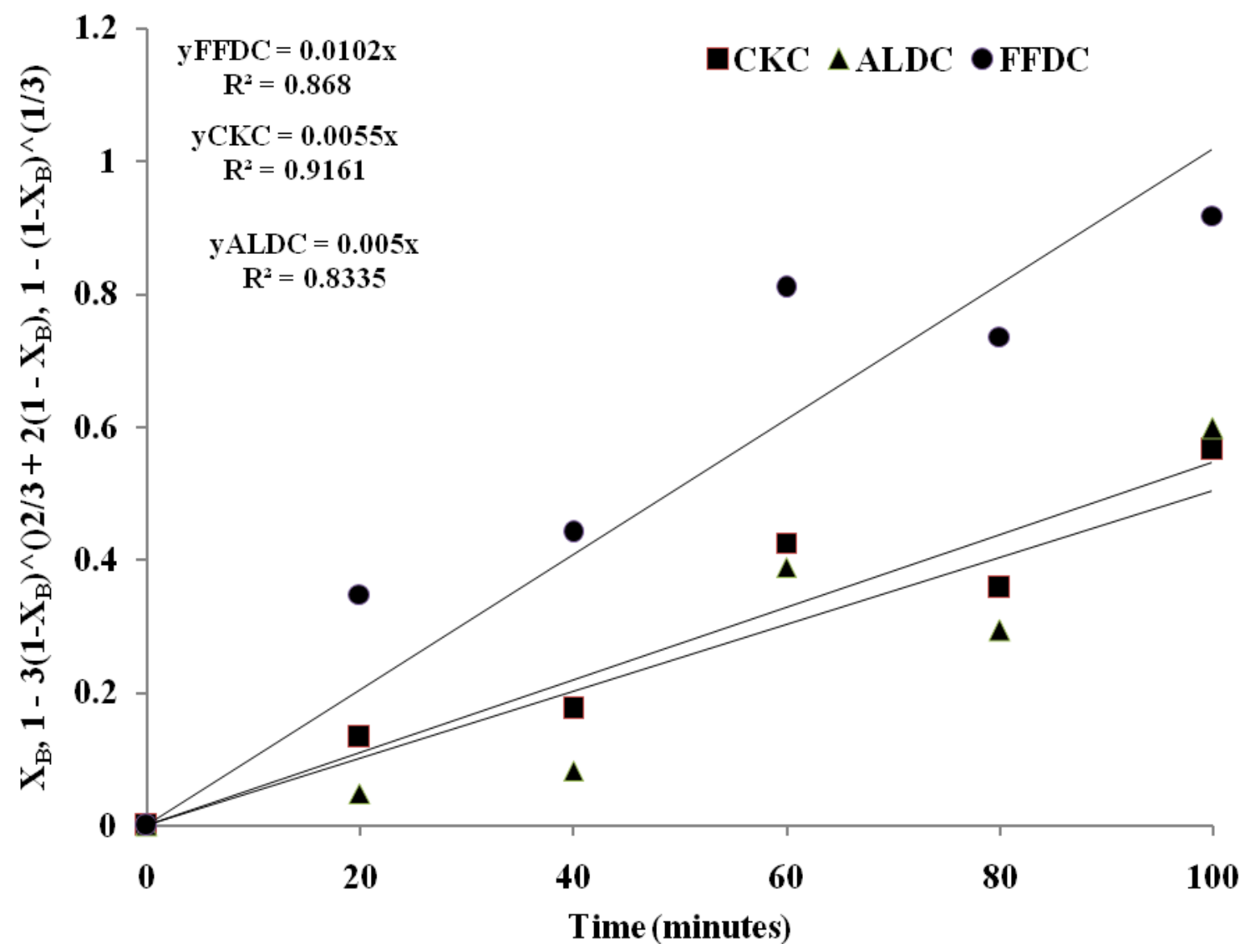

Figure 1. Kinetic modeling of the demineralization of shrimp shell. 


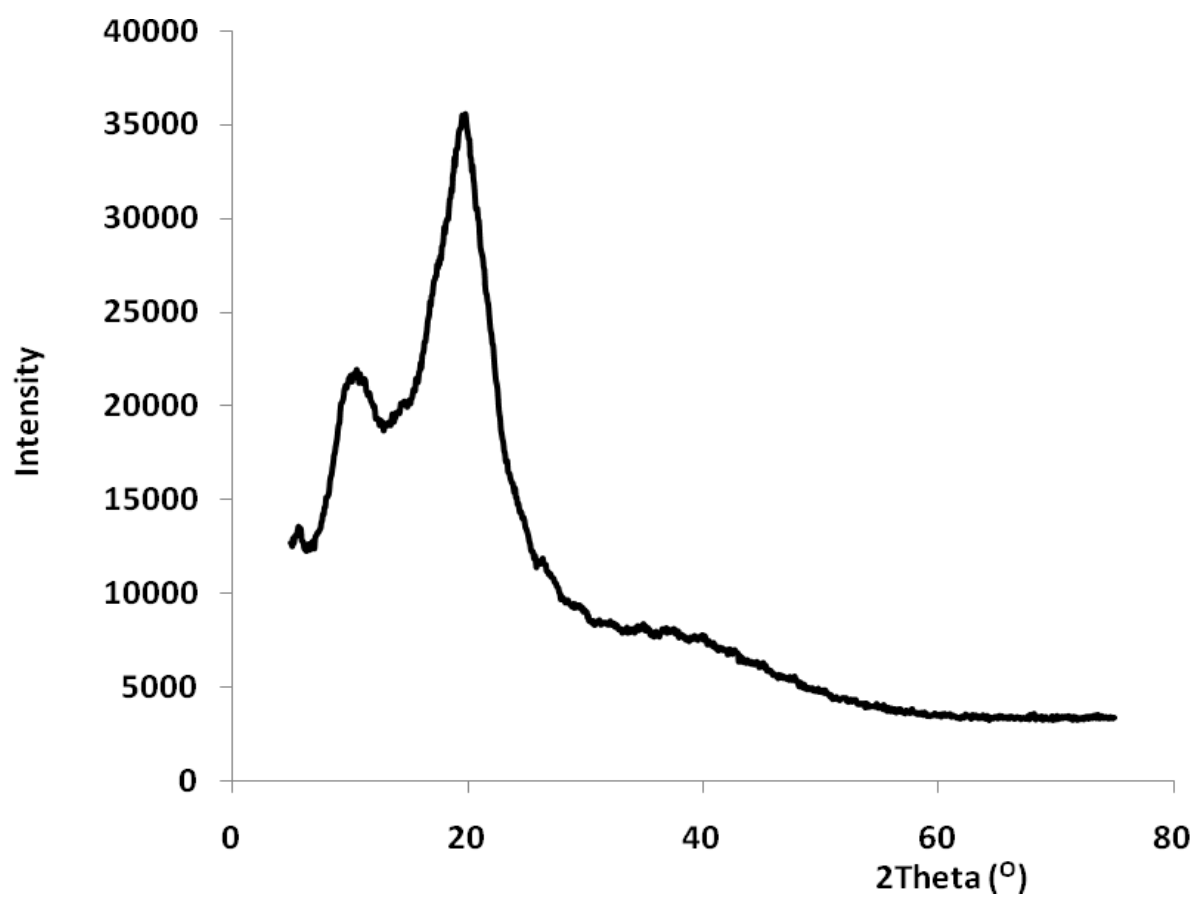

Figure 2. X-ray diffraction pattern of chitosan.

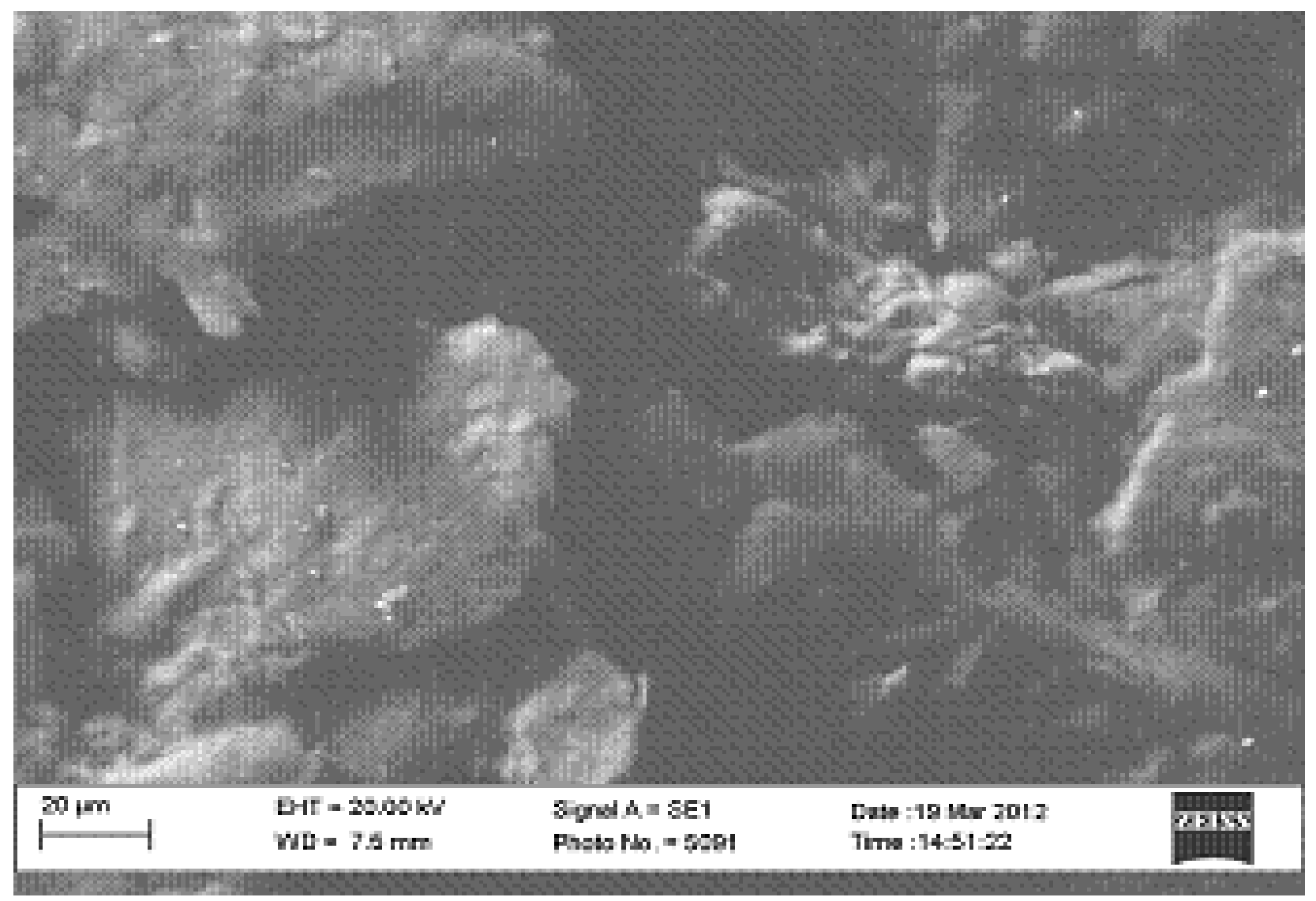

Figure 3. Scanning electron micrograph of chitosan. 
reasons may be advanced for the increase in concentration of $\mathrm{Cd}$.

\section{Demineralization}

Table 3 shows that the composition of $\mathrm{Ca}$ decreased with demineralisation time. The composition of $\mathrm{Cd}$ which was very little at the start increased progressively to $23 \%$ after $100 \mathrm{~min}$ of demineralization. The presence of $\mathrm{Cd}$ in the demineralized shell is probably as a result of accumulation: shellfish are known to accumulate high levels of cadmium due to metallothionein proteins within these organisms that strongly bind to the metals. Therefore, marine invertebrates have high $\mathrm{Cd}$ concentrations derived mainly from food or from the surrounding aquatic medium (Storelli, 2011). Apart from $\mathrm{Ca}$ and $\mathrm{Cd}$, the compositions of the other elements showed an irregular pattern (increasing and decreasing arbitrarily) with time. $\mathrm{Cr}$ which fell below detection in the deproteinized sample appeared in all demineralized sample. Probably, the leaching by $\mathrm{HCl}$ did not affect the Cr present, resulting in an apparent increase.

\section{Kinetic modeling}

Based on the progression in the $\mathrm{Ca}$ content of the demineralized shell with time and because a decrease in composition of $\mathrm{Ca}$ was recorded with time (as against the increase observed with $\mathrm{Cd}$ ), $\mathrm{Ca}$ content was chosen as reference in the kinetic modeling of the demineralization process. The shrinking core model (SCM) was considered as it models fluid-particle reactions (Levenspiel, 1999).

For fluid-film diffusion controlled:

$$
\frac{\boldsymbol{t}}{\tau}=\boldsymbol{X}_{B}
$$

For ash layer diffusion controlled:

$$
\frac{t}{\tau}=1-3\left(1-X_{B}\right)^{2 / 3}+2\left(1-X_{B}\right)
$$

For chemical kinetics controlled:

$$
\frac{t}{\tau}=1-\left(1-X_{B}\right)^{1 / 3}
$$

Where:

$\mathrm{t}=$ reaction time (minutes)

$\mathrm{T}=$ time for complete reaction (minutes)

$X_{B}=$ fractional conversion of solid $B$ (in this case $\mathrm{Ca}$ ) and also defined as:

$$
X_{B}=\frac{(\text { initial concentration of } C a)-(\text { Ca concentration at time } t)}{(\text { initial concentration of Ca })}
$$

As shown in Figure 1, $R^{2}$ values obtained from all three model are fairly good $(>0.83)$. Based on the relative magnitudes of the $R^{2}$ obtained, the chemical reaction controlled mechanism is the best description of the demineralization process $\left(R^{2}=0.9161\right)$. This implies that most of the resistance to the forward reaction (demineralization) lies with the chemical reaction step being much slower that the fluid film diffusion or ash layer diffusion steps. The time for complete conversion ( $\mathrm{T}$ ) for chemical reaction controlled mechanism was determined as $3 \mathrm{~h}$ from Figure 1.

\section{Analysis of chitosan}

The XRD patter of Figure 2 is typical of chitosan. The characteristics peaks of chitosan at $10^{\circ} 2 \theta$ and $20^{\circ} 2 \theta$ (Kohle and Kannan, 2003; Zhetcheva and Pavlova, 2011) are clearly shown. The SEM micrograph of the synthesized chitosan presented in Figure 3 shows the characteristic sheet like layers of deacetylated chitin (Isa et al., 2012).

\section{Conclusion}

The demineralization of shrimps using dilute $\mathrm{HCl}(1.25 \mathrm{~N})$ was modeled as a chemical reaction controlled fluid particle reaction. Based on this kinetic model, the time for complete conversion (or elimination) of calcium was found to be $3 \mathrm{~h}$.

\section{REFERENCES}

Adeleye El, Adubiaro HO, Awodola OJ (2008). Comparability of chemical composition and functional properties of shell and flesh of penauesnotabilis. Pak. J. Nutr. 7(6):741-747.

Das S, Ganesh EA (2010). Extraction of Chitin from Trash Crabs (Podophthalmus vigil) by an Eccentric Method. Curr. Res. J. Biol. Sci. 2(1):72-75

Hirano S (1996). Chitin biotechnology application. Biotechnol. Annu. Rev. 2:237-258.

Isa MT, Ameh AO, Tijjani M, Adama KK (2012). Extraction and characterization of chitin and chitosan from Nigerian shrimps. Int. J. Biol. Chem. Sci. 6(1):446-453.

Kataoka Y (1989). Standardless X-Ray Fluorescence Spectrometry (Fundamental Parameter Method using Sensitivity Library). Rigaku J. $6(1): 33-40$. 
Kato Y, Onishi H, MachidaY (2003). Application of chitin and chitosan derivatives in the pharmaceutical field, Curr. Pharm. Biotechnol. 4(5):303-309.

Kohle P, Kannan RM (2003). Improvement in ductility of chitosan through blending and copolymerization with PEG: FTIR investigation of molecular interactions. Biomacromolecules, 4(1):173-180.

Levenspiel O (1999). Chemical Reaction Engineering, $3^{\text {rd }}$ Edition, John Wiley and Sons, New York, pp. 566-576.

Limam Z, Selmi S, Sadok S, Abed AE (2011). Extraction and characterization of chitin and chitosan from crustacean by-products: Biological and physicochemical properties. Afr. J. Biotechnol. 10(4):640-647.

Mehdinejad MH, Bina B, Nikaeen M, Attar H (2009). Effectiveness of chitosan as natural coagulant aid in removal of turbidity and bacteria from turbid waters. J. Food Agric. Environ. 7(3\&4):845-850.

Murugan R, Ramakrishna S (2004). Bioresorbable composite bone paste using olysaccharide based nanohydroxyapatite. Biomaterials 25(17):3829-3835.

Muzzarelli RAA (1977).Chitin. Pergamon. Press, Oxford, p. 305.

Nicol S (1991). Life after death for empty shells. New Scientist 129:4648.

Poulicek M, Jeunjaux C (1991). Chitin biodegradation in marine environment and experimental approach. Biochem. Syst. Ecol. 107(19):385-399.
Rødde RH, Einbu A, Va'rum KM (2008). A seasonal study of the chemical composition and chitin quality of shrimp shells obtained from northern shrimp (Pandalus borealis), Carbohydr. Polym. $71: 388-393$.

Storelli MM (2011). Cadmium exposure from sea food intake, Encyclopedia of Environmental Health, Elsevier, pp. 456-464.

Takeuchi H, Yamamoto H, Kawashima Y (2001). Muco adhesive nano particulate systems for peptide drug delivery. Adv. Drug Deliv. Rev. 47(1):39-54.

Uno K, Higashimoto Y, Chaweepack T, Ruangpan L (2012). Effect of chitin extraction on residual antimicrobials in shrimp shells. Turk. J. Fish. Aquat. Sci. 12:89-94.

Wang SL, Huang JR (2001). Microbial reclamation of shellfish wastes for the production of chitinases. Enzyme Microb. Technol. 28:376382.

Yadav AV, Bhise B (2004). Chitosan a potential biomaterial effective against typhoid. Curr. Sci. 187(9):1176-1178.

Zhetcheva VDK, Pavlova LP (2011). Synthesis and characterization of a decavanadate/chitosan complex. Turk. J. Chem. 35:215-223. 